\title{
FABRICANDO IDENTIDADES FEMININAS EM ESCOLAS DE ENGENHARIA ${ }^{1}$
}

Karla S. Saraiva ${ }^{2}$

\section{RESUMO}

Nesse trabalho desejåmos trazer alguns fragmentos que nos auxiliem na compreensão da produção da subjetividade feminina em nossa sociedade, mostrando como isso se torna uma barreira para o ingresso das mulheres nas carreiras das engenharias, bem como falar da construção da identidade feminina dentro desses cursos.

Palavras-Chave: Mulheres; Engenharia; Educação.

\section{TRABALHOS DE MULHERES}

Ainda nos dias de hoje, a engenharia segue sendo a profissão que requer formação acadêmica, na qual a marca da masculinidade está mais presente. As mulheres cada vez mais conquistam espaços nos cursos universitários, mas podemos observar uma concentração naqueles ligados ao cuidado do outro e ao que se considera o mundo do lar. São enfermeiras, professoras, psicólogas, nutricionistas. Profissionais cuja competência passa (assim muitos pensam) por aquilo que se tem dito ser "caracteristicas inatas" de nosso gênero, mulheres que sabem zelar pela saúde, educar, cuidar das dores da alma e alimentar, atividades todas essas consideradas ligadas à maternidade, "natural" papel feminino. As mulheres estão representadas equilibradamente nos cursos de direito e medicina, disputando espaços com os homens. Mas ainda são poucas, muito poucas, nas profissões ligadas à tecnologia e à produção, em especial nos cursos de engenharia.

Dizer que a engenharia é profissão "para homens" constitui-se ainda uma afirmativa fácil e freqüentemente aceita.

Mesmo com a força das conquistas femininas, a engenharia continua a ser vista como área reservada aos machos. Afinal persiste a idéia de que as mulheres, seres subjetivos, não se dão bem, por exemplo, com a frieza dos cálculos matemáticos (BERTOLINO, 2003).

Na nossa sociedade está presente a representação de que existem "dois mundos distintos (um mundo público e masculino e um mundo doméstico e feminino)" (LOURO, 1999, p. 70). Negar ou corroborar a existência desses dois mundos, bem como a existência das características ligadas aos gêneros, não é nossa preocupação nesse artigo. Desejamos, sim, problematizar o caráter natural dessas representações, apresentando-as como construções culturais.

Trabalho apresentado no II Seminário Internacional de Educaçāo Intercultural, Gênero e Movimentos Sociais, realizado em Florianópolis, em 2003.

2 Doutoranda em educaçāo (UFRGS), engenheira civil e professora do curso de Engenharia Civil da UNISINOS. 
Entendemos que a linguagem não é uma simples representação das "coisas como elas são", não havendo, portanto, boas e más representações, mais ou menos eficientes em captar a essência da "realidade". Ainda que haja uma materialidade, prévia a qualquer sistema de significação, o mundo não existe para os sujeitos enquanto esse não constrói significados. Isso só é possivel pela linguagem. Dentro dessa perspectiva, a linguagem ultrapassa seu papel de representação, assumindo um papel ativo de produtora das coisas. As representaçỏes estão implicadas em relações sociais e de poder, entendendose estas implicações numa dimensão muito mais ampla que a "distorção da realidade". As representações, instituidas através destas relações, constituem e formam o "real" e o "verdadeiro". Representar a engenharia como uma profissão característica do gênero masculino acaba por constituí-la como tal.

\section{PROCESSOS DE FABRICAÇÃO DE SUBJETIVIDADES E A ESCOLA}

O lluminismo inventou o Homem, o sujeito do cogito cartesiano (que pensava, por isso existia); que necessitava ser emancipado para dar vazão a sua essência. Em nome desse sujeito transcendente denunciou-se um poder repressivo, que turvava seu conhecimento e impedia sua libertação.

A contemporaneidade vem libertar-nos da liberdade. Larrosa (2000), apoiando-se no pensamento foucaultiano, subverte o significado usual da palavra liberdade. Rompe com uma tradição que entende a liberdade como um retorno a uma origem, como a busca de uma essência primeira do homem, como sua emancipação de forças que o amarram, constrangem e impedem o exercício do livre-arbítrio. Coloca a liberdade do lado da experiência, do cotidiano e das pequenas resistências. O pensamento pós-moderno é antes de tudo fragmentário, disperso, espalhando em estilhaços as verdades universais. Se algum ponto em comum podemos identificar nesses fragmentos, é a desconstrução das metanarrativas iluministas ${ }^{3}$, dentre elas a existência de um "eu verdadeiro" e da própria verdade. Para Larrosa (1999, p. 40-41) "... a idéia do que é uma pessoa, ou um eu ou um sujeito, é histórica e culturalmente contingente, embora a nós, nativos de uma determinada cultura e nela constituidos nos pareça evidente e quase 'natural' esse modo tão 'peculiar' de entendermos a nós mesmos". O sujeito se constitui dentro de uma determinada cultura, a partir de verdades construidas nesse mundo. Para Costa (2000, p.76) "aquilo que chamamos de 'verdade' é produzido na forma de discursos sobre as coisas do mundo, segundo regimes regidos pelo poder". A partir da "virada lingüística"4 passamos a compreender que a linguagem mais do que representar o mundo, ela o constitui.

Conforme Veiga-Neto (2000, p. 45) "foi Lyotard, ao dizer no início dos anos 70 que os pressupostos sobre os quais se assenta a modemidade não são uma descoberta do lluminismo, mas uma invenção do próprio lluminismo, isto é, uma construção geograficamente localizada e historicamente datada... $\mathrm{O}$ caráter legitimador das narrativas modernas que permite que ele denomine grandes narrativas ou metanarrativas - a saber um sujeito transcendental que estaria sempre presente em cada um de nós, à espera de um aperfeiçoamento pela emancipação progressiva da razão",

4 A chamada "virada lingüistica" tem origem no trabalho de Wittgenstein. A linguagem deixa de ser entendida como uma representação do "mundo" e da "realidade", e passa a ser compreendida como aquilo que produz o mundo e a realidade, instituindo significados (VEIGA-NETO, 1996). 
Não existem significados fora da linguagem. Aquilo que chamamos verdade é produto de discursos, enunciados dento de relações de saber-poder.

Um dos autores que mais contribuíram nesse processo desconstrutivo da verdade foi Michel Foucault. Sua obra nos mostra como nossa subjetividade é construída por práticas discursivas, no interior de relações de saber-poder, trazendo uma compreensão de poder que desloca seu significado de mecanismo de repressão para mecanismo de coerção.

O tema do poder assume lugar central na obra de Foucault, aparecendo diversas vezes, mas, principaimente em Vigiar e Punir (1999). Ai ele mostra que a regulação das sociedades de soberania era exercida pela violência sobre os corpos, por um poder repressivo, por um poder de força e de coação. Com o crescimento da população e das revoltas, os mecanismos de exercício de poder dão lugar a outros mais sutis.

Na idade modema, o controle das populações precisa ser realizado através de novos dispositivos mais adequados a esses tempos. Dispositivos capazes de produzir corpos dóceis, maximizando sua força de trabalho e minimizando sua força política, sua força de resistência. Não mais como algo que se possui, mas se exerce na relação. Poder que submete não por coação e proibição, mas por meio da produção de discursos de verdade, que por positivos e produtivos ao nivel do desejo e do saber dominam coercitivamente. Esse poder está intimamente articulado com o saber. Sobre esse ponto, Costa $(2000, p .77)$ escreve: "Conhecer o que deve ser governado é parte da estratégia que permite as regulações e o controle dos indivíduos".

O poder disciplinar para funcionar impõe uma visibilidade permanente sobre aqueles que devem ser controlados, separando-os num espaço quadriculado e determinando o uso de seu tempo. Essa vigilância tem por objetivo comparar, hierarquizar e impor sanções. O poder disciplinar é uma prática normativa, sendo a norma compreendida como um tipo particular de regra, uma maneira de produzir, um princípio, um jogo de valores. A norma cria o normal e o anormal, o normal e o patológico. A norma é criação de um grupo e sua validade é sempre finita e mortal, pois se atualiza constantemente, acompanhando as mudanças culturais. O poder disciplinar subjetiva.

Entre os múltiplos dispositivos disciplinares, a escola (e a academia, por extensão) é um espaço privilegiado para construção de subjetividades e corpos dóceis, tanto por sua abrangência, quanto pela legitimidade que é conferida a seus enunciados. Veiga-Neto (2000) nos mostra que Kant já identificava essa potencialidade quando escreveu que as crianças devem ir à escola, antes de tudo, para aprender disciplina (cumprir horários e ficar tranqüilas nos seus lugares), considerando o aprendizado da cultura como fator secundário.

O currículo há muito não pode ser ingenuamente definido como uma coletânea desinteressada de saberes. As teorias críticas do currículo desde a década de 60 já trazem as relações de poder para dentro desta discussão. Mas, para os partidários de teorias críticas, o poder é visto como algo externo que distorce o conhecimento, a aprendizagem e as relações sociais, algo que emana de um pólo (governo, classe dominante, professores, ...) e cujas marcas devem ser apagadas.

Assumindo os pressupostos do campo dos estudos culturais articulados ao pensamento foucaultiano, entendemos o curriculo como um artefato cultural 
que, muito mais do que organizar conteúdos a serem aprendidos, funciona como um instrumento de rodução de sujeitos. Porém, partindo da idéia de um poder capilar, disseminado em todas as relaçōes sociais, parece-me ingênuo e utópica a idéia de um currículo (e de uma escola, por extensão) sem relaçōes de poder. Essas relaçōes vão produzir determinados sujeitos. O currículo faz muito mais que transmitir saberes. Para Popkewitz (1999, p. 174) "Aquilo que está inscrito no currículo não é apenas informação - a organização do aconhecimento corporifica formas particulares de agir, sentir, falar e 'ver' o mundo e o 'eu'".

Entendemos, assim, a escola e o currículo como produtores daquilo que somos. Para Silva (1999, p. 150) “o currículo é documento de identidade". Não existem, pois, práticas pedagógicas, sejam na família, na escola, ou em qualquer outro lugar, que possam acontecer sem um exercício de poder e alguma forma de subjugação. Devemos, sim, perguntar que verdades e que subjetividades estamos produzindo e por meio de que mecanismos.

Ainda que se possam reconhecer os mecanismos de que a escola se vale para produção de subjetividades consideradas adequadas para o cumprimento das funçōes sociais, "isso não deve ser entendido como de modo intencional, ardiloso" (VEIGA-NETO, 1996, p. 249). Antes que se tome como causa imanente, "a saber, aquela que funciona como se dobrando sobre si mesma, de modo que, em seu efeito, se transmuta, se atualiza, se integra e se diferencia de si mesma" (id., p. 223).

\section{FABRICANDO MULHERES}

Desde a infância, mesmo antes de irmos para escola, começamos a aprender o que é "ser mulher" e que isso é diferente de "ser homem". Já na família aprendemos as tarefas, os lugares e os comportamentos de mulher. Estas marcas continuam a serem produzidas no ambiente escolar. Lá nos ensinam quais tarefas "cabem" à mulher, quais as profissōes "adequadas", quais os "dons naturais" que possuímos, quais as características "inatas" de nosso gênero. Aprendemos que homens e mulheres devem ocupar diferentes lugares na estrutura social e para isto devem desenvolver diferentes habilidades e adquirirem diferentes saberes.

A subjetividade é fraturada e contingente. Os diversos discursos que nos atravessam fazem com que ocupemos posiçōes de sujeito sempre provisórias e em constante deslocamento. Falar de uma identidade feminina é bastante problemático, visto que somos muitas, cada uma única, combinando gênero, raça, etnia, classe e a cultura em que nos inserimos, bem com nossas concordâncias e resistências. Ainda assim, devemos reconhecer que o gênero e todas suas implicaçōes normalizadoras são os grandes marcadores identitários que carregamos. Antes de qualquer outra definição, somos homens ou mulheres, conceitos que nos parecem simples fatos biológicos, mas que carregam toda uma construção cultural datada e localizada. A marca do gênero é tão forte que se inscreve já no nosso nome, fazendo que seja a primeira informação que alguém tenha sobre nós. Sermos homens ou mulheres nos insere numa lógica binária, onde só há lugar para as subjetividades normais - a saber, a subjetividade heterossexual. Para Swain (2002, p. 326) "é a prática da sexualidade, portanto, 
que organiza o 'eu' e faz de mim uma identidade inteligível... Temos assim mulheres, homens - identidades definidas num esquema binário, heterossexual, reprodutivo 'natural'- rodeados de uma multidão de práticas que traduzem identidades incompletas, incorretas, incômodas".

Somos convidados e convidadas a nos narrar como homens ou mulheres e a aderir a um discurso normalizador. Nessas narrativas, a identidade feminina é construida como dobra da identidade masculina, assinalando-se rupturas e descontinuidades em relação àquela hegemônica. Assim, passamos a nos reconhecer como desviantes da normalidade. "A constituição de um sujeito 'mulher' atravessou toda uma reflexão teórica articulada aos movimentos feministas em diferentes países ocidentais e empenhou-se em desmantelar a construção 'natural' do feminino apenas como o 'Outro' do homem" (SWAIN, 2000, p. 140).

Uma idéia que circula com força na sociedade ocidental apresenta o homem como tendo um sexo e a mulher como sendo um sexo (SWAIN, 2000). O "ser mulher" se cristaliza e nos é apresentado como sendo uma forma essencial. Esse ser tem como habitat o lar, sendo dócil, frágil, sensível e passiva (características de pouco valor no mundo capitalista). Apresenta, ainda, um déficit de raciocínio e decisão em relação ao homem. Essa representação de mulher está tão naturalizada que até mesmo algumas feministas, ao invés de problematizar essa própria construção, aceitam-na, apenas reivindicando uma valorização dessas "naturais características femininas". Entretanto, conforme afirma Swain (2000, p. 142),

... a historicidade das práticas discursivas mostra a contingência das representações sociais, da inteligibilidade instituida em imagens de corpo, em funções definidas, em papéis sexuados cuja objetivação constrói a realidade que supostamente refletem. Os discursos sobre o corpo e a sexualidade e a divisão hierarquizados seres humanos em mulheres e homens são, de fato, efeito e instrumento de poder instituinte.

\section{FABRICANDO ENGENHEIRAS}

Se desde cedo aprendemos que somos pouco dotadas para o raciocínio abstrato, para o trato com o mundo da produção, para liderança e para tomadas de decisão. Optar por um curso de engenharia para nós significa aceitar o desafio de ultrapassar nossas "limitações". Para entrar nesse território masculino, acreditamos ser necessário deixar lá fora muitas daquelas marcas, que desde sempre nos foram ditas serem características das "verdadeiras mulheres", seja pela escola, pela família ou pela mídia.

Para nós, mães zelosas, afetivas, frágeis e sensiveis, os saberes, habilidades e comportamentos que exigem o exercício da engenharia só poderão ser obtidos através de muito esforço e disciplina... Embora não existam interdições implicitas, legais, ao ingresso das mulheres nos cursos de engenharia, as construções discursivas nos colocam como devedoras de atributos. Faz com que se erga uma barreira, muito mais difícil de ser contestada e gerando muito 
menor resistência que gerariam proibições e interditos, pois justificada por histórias bem naturalizadas. Afinal, o senso comum pensa que essa essência feminina é uma descoberta (da medicina, da psiquiatria e da observação empírica) e não uma invenção da nossa cultura.

O poder exercido pela via repressiva e pela violência é cada vez mais condenável. Atos como o Massacre de Montreal ${ }^{5}$ causam não apenas comoção coletiva e atos de repúdio, como também movimentos de solidariedade (no caso, foi fundado o movimento White Ribbon - fita branca - por homens que repudiam a violência contra a mulher e o demonstram portando laços de fita branca). Os discursos politicamente corretos de inclusão e igualdade entre os gêneros muitas vezes geram ações afirmativas. Nos Estados Unidos e na Europa, muitas universidades têm planos específicos para aumentar a participação de mulheres, normalmente oferecendo facilidades, como reservas de vagas.

Não entendo ser esse o melhor caminho. Mais do que evitar atos violentos e criar políticas de inclusão, devemos desenvolver ações que tornem possível produzir subjetividades fora dos estereótipos atualmente aceitos (não apenas para mulheres, mas para negros, homossexuais, minorias étnicas e outros grupos que encontram-se cristalizados em discursos que não lhes deixam muitas brechas). A inclusão feita sem que se pense nessas questões da identidade é uma inclusão excludente (VEIGA-NETO, 2001), pois incluímos as mulheres, mas as deixamos marcadas com a anormalidade, colocando-as em comparação com os colegas homens e apontando suas deficiências. Assim acredito, que a principal razão do reduzido número de mulheres em cursos de engenharia ${ }^{6}$ seja justamente a suspeita que as mulheres carregam de sua pouca capacidade.

Para termos alguma chance de sermos reconhecidas como profissionais capacitadas devemos reconstruir nossa subjetividade, o que acontece em quase todas profissões. Porém, no caso de mulheres engenheiras essa reconstrução passa por conflitos, porque em muitos pontos temos que virar as costas para o modelo de mulher que nos ensinaram até então. Valores e comportamentos que capturaram nossa alma ${ }^{7}$ e inscreveram-se sobre nosso corpo deverão ser modificados, esquecidos, redirecionados, produzindo, por fim, a engenheira. Esse conflito só não é mais doloroso, pois na maioria das vezes acreditamos que isso "nos faz crescer como seres humanos". Deixar as "futilidades femininas" para trás e cultivar as "qualidades" masculinas é compreendido como um avanço pelas próprias mulheres, num reconhecimento tácito da superioridade masculina.

5 No dia 6 de dezembro de 1989, quatorze mulheres, estudantes de engenharia, foram assassinada na Ecole Polytechnique da Universidade de Montreal. O assassino justificou o massacre (chama em inglês gendercide: massacre de gênero) como um protesto pela sua não aceitação de que as mulheres estejam ocupando lugares masculinos na sociedade. Para maiores detalhes veja www.gendercide.org/case_montreal.html.

6 A reduzida presença de mulheres nos cursos de engenharia não é observada apenas no Brasil, mas em vários outros paises (näo digo todos por falta de dados). No Brasil apenas $13 \%$ dos profissionais desse campo são mulheres (BERTOLINO, 2003) e no Canadá, 19\%, número que

7 cresceu bastante após o massacre de Montreal (Gendercide, 2003)

7 Uso aqui alma não no sentido cristão, mas no sentido foucaultiano: "Não se deve dizer que a alma é uma ilusão, ou um efeito ideológico, mas afirmar que ela existe, que tem uma realidade, que é produzida permanentemente, em torno, na superfície, no interior do corpo pelo funcionamento de um poder... Realidade histórica dessa alma, que, diferentemente da alma representada pela teologia cristã, não nasce faltosa e merecedora de castigo, mas nasce antes de procedimentos de puniçăo, de vigilância, de castigo e de coação..." (FOUCAULT, 1999, p. 28). 
Para essas, o caminho da emancipação passa pela construção de uma subjetividade dentro do padrão masculino hegemônico, sem problematizar esse "modelo tamanho único".

A academia é olugar onde aprendemos nossa profissão: ser engenheiro(a) implica em conhecer muito mais que regras de cálculo, modelos de produção e técnicas industriais. Ser engenheiro(a) implica em conhecer as regras de comportamento que nos deixam reconhecer como tais - saber como falar, como agir, como pensar, çomo se mover, como se vestir, ... Estas regras não estão, em geral, escritas em livros e manuais. São aprendidas, de modo sutil, no dia-adia da vida acadêmica e reforçadas pelos contatos com o mundo do trabalho. Agir conforme se espera que um engenheiro aja é um dos requisitos para o sucesso profissional.

Se as regras que dizem respeito a como um engenheiro deve-se comportar não estão explícitas, menos ainda aquelas concernentes às engenheiras. Impõese, a essas profissionais, como padrão único desejável o comportamento aceito na sociedade não apenas como masculino, mas como masculino hegemônico, referente a homens heterossexuais. Parece que se deseja pelo silêncio negar as possibilidades destes sujeitos "diferentes" participarem do grupo de engenheiros - diferente aqui entendido como desviantes da "normalidade". A negação da participação das mulheres pode ser percebida, por exemplo, no fato de, até 1988, não existir no Brasil o título de engenheira. Até este ano éramos todas, gostássemos ou não, "engenheiros". O trabalho feminino nestaárea ganha, então, pelo menos o reconhecimento legal de sua existência.

Um artigo publicado na Internet tem como título "Tecnisa contrata mulheres para 'funções' masculinas'" (OBRACADABRA, 2003). O artigo apresenta como uma inovação a decisão da empresa em contratar especificamente mulheres para o que se chama pós-obra, ou seja, prestação de assistência aos clientes após a aquisição do imóvel. A idéia partiu de uma engenheira, gerente da empresa, que assim justifica: "Nós optamos assim avaliando procedimentos típicos da natureza feminina, que incluem a realização de tarefas com mais dedicação, simpatia e cordialidade. Apesar do pós-obra implicar num certo desgaste físico..." (grifos nossos) (OBRACADABRA, 2003). Observamos aqui que essa gerente, ela própria mulher, reforça os estereótipos de dedicação, sensibilidade, bem como a fragilidade feminina, mesmo assumindo uma posição de valorização dos atributos iniciais e a confiança na superação de sua "fragilidade".

Podemos observar nas alunas (e colegas e em mim mesma) uma luta constante para superarem suas "deficiências" e não parecerem "muito femininas". A própria aparência das estudantes, em sua maioria, ao longo do curso vai perdendo as marcas de feminilidade que nossa sociedade inscreve nos corpos, o que se nota pelas formas de vestir, pela escolha de complementos e pelo própriogestual. Esse fato também é freqüentemente notadoentre as profissionais. Parecem querer mostrar com essas outras marcas de corpo, que estão adquirindo as necessárias competências da engenharia.

A maioria das alunas trabalha com mais empenho e afinco e apresenta desempenhos superiores àqueles de seus colegas homens, ainda que se possa constatar uma menor confiança em seus resultados. Louro (1999, p. 69), cita um estudo de Walkerdine comparando o desempenho de meninos e meninas na matemática, onde as meninas eram "acusadas de ir bem porque trabalhavam 
muito, seguiam regras, comportavam-se bem". O bom desempenho dos meninos era decorrência simplesmente de sua inteligência e capacidade. Esta afirmativa me parece válida também para o contexto dos cursos de engenharia. Esses discursos colocam em movimento um processo de subjetivação das estudantes, que passam a se reconhecer como estudiosas e particularmente vocacionadas para o campo da pesquisa e da docência (o que lhes permite escapar do mundo tabu da produção). Articulando os discursos que circulam dentro das escolas de engenharia com aqueles provenientes de outros lugares, que investem em representações do feminino ligadas à docilidade e à passividade, em especial os veiculados pela midia. "Essa política cultural que tem como alvo as identidades incide de forma particularmente intensa em um campo ocupacional marcado por históricas vinculações com o gênero feminino - a docência" (COSTA, 2000, p. 75).

Como resultado temos a bem sucedida produção da "vocação" acadêmica feminina. As taxas de mulheres em cursos de mestrado e doutorado em engenharia, bem como na carreira da docência, excedem bastante àquelas observadas em cursos de graduação.

O mundo masculino é público e o mundo feminino é privado. Costa, comentando as representações de professores na Revista Nova Escola, diz a esse respeito; "Enquanto os professores são apresentados como habitantes 'naturais' dos espaços públicos - museus, teatros, bosques, canchas esportivas - as professoras, por sua vez, são expostas, predominantemente, em ambientes escolares internos" (2000, p. 85). Acredito que o mesmo acontece no exercício da engenharia. Aquelas mulheres que não permanecem na universidade como docentes, participam com mais freqüência em atividades internas (projetos, planejamento e ornamentação, por exemplo), do que em atividades ditas de campo (execução de obras, controle de produção, manutenção de máquinas,...).

Dentre os cursos de engenharia, pelo menos um apresenta um número de mulheres igual e até superior ao de homens: Engenharia de Alimentos. Compreensivel, já que alimentos não parecem produtos industriais (ainda que o sejam), mas produtos ligados à vida do lar.

Ainda que as mulheres que freqüentam cursos de engenharia utilizem estratégias para desconstruir as marcas socialmente representadas como características femininas, a representação que pertence ao "mundo doméstico", que tem como função primeira a reprodução e que operam pela "lógica do coração" persiste. Um dos raros trabalhos que encontramos sobre a participação feminina nas engenharias encontra-se num site da empresa Schlumberger Limited (2003). Aí, é apresentada uma pesquisa feita através de um questionário respondido por 11 profissionais ligadas às engenharias, provenientes de diversos países da Europa e dos Estados Unidos. Uma das questões, "Qual foi o impacto de sua opção de carreira na sua vida familiar?", remete justamente a essa ligação com o mundo doméstico e com o cuidado da familia. Numa pesquisa com homens jamais seria formulada tal questão. Costa (2000, p. 85), cita a argumentação de Perrot: "impelir as pessoas à esfera do privado é uma tentativa de diminuir seu poder na incursão sobre os assuntos públicos, reduzindo sua participação no controle social". 
Uma segunda articulação do trabalho feminino na engenharia e o mundo privado encontra-se em Plonski (2003), num trabalho sobre a necessidade da educação continuada em engenharia.

\begin{abstract}
A sétima causa de demanda por educação continuada prende-se à trajetória pessoal e profissional das engenheiras. Dado o modelo de relações sociais de gênero vigente na sociedade brasileira, a responsabilidade pelo lar è predominantemente da mulher. Assim, é comum engenheiras largarem a sua atividade profissional por mais de décađa após o nascimento da primeira criança. Quando do seu retorno, após terem-se liberado de parcela substancial da ocupação com os afazeres domésticos, é quase certo que necessitarão de um programa de educação continuada para a sua reinserção profissional.
\end{abstract}

Acredito que esta passagem poderia ser modificada, citando apenas engenheiros, de qualquer gênero, que tenham se afastado do exercício da engenharia por longos períodos, evitando essa vinculação da mulher com sua "natural" (e até "louvável") dedicação maternal.

Conforme mostramos anteriormente, as mulheres ainda sofrem discriminações e se encontram em posição de desvantagem no exercício profissional da engenharia. Desconfianças em relação à competência e representações de uma "inata" deficiência de capacidade, principalmente em atividades de campo, ainda são muito freqüentes (até prova em contrário, mulheres são incompetentes, assertiva contrária quando se refere a um homem). Podemos ler o testemunho de uma engenheira no site da Obracadabra (2003) como uma ilustração dessa afirmativa: "Nessa função [pós-obra], é mais fácil ser aceita, principalmente porque a empresa está receptiva à presença feminina em seu quadro de engenheiros. Na outra atividade [execução de obras] sofri muita discriminação, até mesmo de clientes. Eles não aceitavam uma mulher à frente de uma obra".

Mesmo assim, muitas negam sentir-se atingidas por mecanismos de exclusão. Acredito que isso aconteça porque esses mecanismos utilizam estratégias de poder tão sutis que não conseguem ser percebidos. A naturalização de papéis e lugares femininos colabora com isso, bem como um certo pudor de falar de discriminação, passando uma idéia de fragilidade. Naquele mesmo site de entrevista da empresa Schlumberger Limited, encontramos outra pergunta que vale analisar: "Você já enfrentou uma situação profissional na qual o fato de ser mulher resultou em tratamento desigual para você ou seu trabalho? Como você lidou com a situação?". A maioria das entrevistadas negava ter passado por qualquer situação desse tipo. Algumas narram fatos claramente discriminatórios, para em seguida minimizá-los, tratando-os como casos isolados e pouco significativos.

Não podemos deixar de concordar com Costa (2000, p.75): “Ainda vivemos em uma sociedade elitista e discriminadora, tributária do patriarcado, em que protagonistas do gênero feminino entre outros(as), são alvos de variados mecanismos de exclusão, constrangimento e coerção". Difícil negar o caráter discriminatório na representação do trabalho feminino nas engenharias. 
Nesse artigo procurei mostrar como as identidades cristalizadas que se têm construido sobre a mulher vêm influenciado suas opções profissionais e as dificuldades que criam para o ingresso das mesmas em cursos de engenharia, bem como o preço que devemos pagar quando, apesar de tudo, optamos por essa carreira. Numa sociedade constituída pelos valores modernos e movida pela dicotomia, muitas vezes parece que penetrar em universos tidos como masculinos representa a máxima transgressão. Reconhecemos que estas atitudes foram e são importantes para ampliar o espaço da mulher na vida pública. Porém, devemos avançar, lutando para problematizar essa mulher essencial que um dia inventaram, pois, só assim, nossos espaços poderão ser efetivamente ampliados. Ainda que saibamos que toda educação é um mecanismo de produção de subjetividade, nós professores devemos estar tão (ou mais!) atentos àquilo que estamos produzindo nos alunos do que àquilo que esses alunos estão produzindo com o conhecimento. Porque podemos encontrar "a liberdade não nas obrigações mútuas de sujeitos racionais de obedecerem a leis morais universais, mas em nossa real capacidade de mudar as práticas em que somos constituídos ou nos constituímos como sujeitos morais" (RAJCHMAN, 1987, p. 90).

\section{REFERENNCIAS BIBLIOGRÁFICAS}

BERTOLINO, E. Mulheres na construção. Disponivel em <http://www2.uol.com.br/ simbolo/ raca/0800/ compoa1.htm> (consulta realizada na Internet em fevereiro de 2003).

COSTA, M.V. Midia, magistério e política cultural. In: Estudos Culturais em Educação. Porto Alegre: UFRGS, 2000, p. 73-91.

FOUCAULT, M. Vigiar e Punir. $21^{\text {a }}$ ed. Petrópolis: Vozes, 1999.

GENDERCIDE WATCH. Case study: Montreal massacre. Disponivel em <http:// www.gendercide.org/case montreal.html> (consulta realizada na Internet em fevereiro de 2003).

LARROSA, J. Tecnologias do eu e educação. In: SILVA, T.T. O Sujeito da educação estudos foucaultianos. $3^{\mathrm{a}}$ ed. Petrópolis: Vozes, 1999, p. 35-86.

. Alibertação da liberdade. In: PORTOCARRERO, V. e CASTELO BRANCO, G. Retratos de Foucault. Rio de Janeiro: Nau, 2000, p. 328-344.

LOURO, G.L. Gênero, sexualidade e educação - uma perspectiva pós-estruturalista. $3^{a}$ ed. Petrópolis: Vozes, 1999.

OBRACADABRA. TECNISA contrata mulheres para "funçôes masculinas". Disponivel em $<$ http://www.obracadabra.com.br/releases.asp?Release $=340>$ (consulta realizada na Internet em fevereiro de 2003).

PLONSKI, G.A. Educação continuada e reciclagem de professores e engenheiros. Disponivel em <http://www.engenheiro2001.org.br/programas/980208a1.htm> (consulta realizada na Internet em fevereiro de 2003).

POPKEWITZ, T.S. História do currículo, regulação social e poder. In: SILVA, T.T. O sujeito da educação - estudos foucaultianos. $3^{a}$ ed. Petrópolis: Vozes, 1999, p. 173-210.

RAJCHMAN, J. Foucault: a liberdade da filosofia. Rio de Janeiro: Jorge Zahar, 1987.

Schlumberger Limited. Mulheres na ciência e na engenharia. Disponivel em <http:/ www.slb.com/seed/pt/ career/wise/s

SWAIN, T.N. Quem medo de Foucault? Corpo e sexualidade. In: PORTOCARRERO, V. e CASTELO BRANCO, G. Retratos de Foucault. Rio de Janeiro: Nau, 2000, p. 138-158. 
SWAIN, T.N. Identidade nômade: heterotopias de mim. In: RAGO, M., ORLANDI, L.B.L. e VEIGA-NETO, A. Imagens de Foucault e Deleuze - ressonâncias nietzschianas. Rio de Janeiro: DP\&A, 2002, p. 325-340.

VEIGA-NETO, A. A ordem das disciplinas. Porto Alegre: UFRGS (Tese de Doutorado), 1996.

Michel Foucault e os estudos culturais. In: COSTA, M. Estudos culturais em educaçāo. Porto Alegre: UFRGS, 2000, p. 37-72

VEIGA-NETO, A. Incluir para excluir. In: LARROSA, J. e SKLIAR, C. Habitantes de Babel - politicas e poéticas da diferença. Belo Horizonte: Autêntica, 2001, p. 105-118. 